\title{
Stage I testicular seminoma risk-adapted therapeutic management
}

\author{
Bela MRINAKOVA ${ }^{1,2, *}$, Karol KAJO ${ }^{3}$, Viera LEHOTSKA ${ }^{4}$, Martina ONDRUSOVA ${ }^{5}$, Sona BALOGOVA ${ }^{6}$, Zuzana PINAKOVA ${ }^{1,7}$, Vera NOVOTNA ${ }^{1,2}$, \\ Vanda USAKOVA ${ }^{2}$, Lucia FEDORKOVA ${ }^{1,2}$, Iveta WACZULIKOVA ${ }^{8}$, Juraj KAUSITZ ${ }^{9}$, Dalibor ONDRUS ${ }^{1}$ \\ ${ }^{1} 1^{\text {st }}$ Department of Oncology, Comenius University, Faculty of Medicine and St. Elisabeth Cancer Institute, Bratislava, Slovakia; ${ }^{2}$ Department \\ of Medical Oncology, St. Elisabeth Cancer Institute, Bratislava, Slovakia; ${ }^{3}$ Department of Pathology, Slovak Medical University, St. Elisabeth \\ Cancer Institute, Bratislava, Slovakia; ${ }^{4} 2^{\text {nd }}$ Department of Radiology, Comenius University, Faculty of Medicine and St. Elisabeth Cancer In- \\ stitute, Bratislava, Slovakia; ${ }^{5}$ Pharm-In, Ltd., Bratislava, Slovakia; ${ }^{6}$ Department of Nuclear Medicine, Comenius University, Faculty of Medi- \\ cine and St. Elisabeth Cancer Institute, Bratislava, Slovakia; ${ }^{7}$ Department of Radiation Oncology, Slovak Medical University and St. Elisabeth \\ Cancer Institute, Bratislava, Slovakia; ${ }^{8}$ Department of Nuclear Physics and Biophysics, Division of Biomedical Physics, Comenius University, \\ Faculty of Mathematics, Physics and Informatics, Bratislava, Slovakia; ${ }^{9}$ Department of Radioimmunodiagnostics, St. Elisabeth Cancer Institute, \\ Bratislava, Slovakia
}

*Correspondence: bela.mrinakova@ousa.sk

Received June 30, 2020 / Accepted December 7, 2020

\begin{abstract}
Following orchiectomy, patients with clinical stage I (CSI) testicular seminoma may be managed by active surveillance (S) or adjuvant treatment (radiotherapy or chemotherapy). In view of the published data on long-term toxicity, especially second malignant neoplasms (SMNs), adjuvant radiotherapy (ART) is currently no longer recommended as an adjuvant therapy option for these patients. The purpose of our recent study was to compare the impact of two selected treatment approaches - S versus adjuvant chemotherapy (ACT) on the survival of patients with CSI testicular seminoma. This crosssectional study analyzed a total of 139 patients collected at a single center between 10/2011-5/2020, with CSI testicular seminoma, stratified into two groups according to risk-adapted therapeutic approaches. In the S group (low-risk - without rete testis invasion - RTI, primary tumor size $<4 \mathrm{~cm}$ ), consisting of 77 patients, who underwent S, relapse occurred in 10 (13.0\%) patients after a mean follow-up of 14.3 months. In the ACT group (high-risk - RTI and/or primary tumor size $>4$ $\mathrm{cm})$, consisting of 62 patients, who were treated with ACT, relapse occurred in $5(8.1 \%)$ patients after a mean follow-up of 11.6 months. Overall survival of patients in both groups was $100 \%$ with a mean follow-up of 43.9 months. A statistically significant difference in progression-free survival (PFS) between these two groups was not found. Based on our findings, ACT seems to be an adequate treatment for patients with a high risk of relapse, as well as $S$ for those with a low risk of relapse. Despite its excellent prognosis, optimal management of CSI testicular seminoma remains controversial, with variations in expert opinion and international guidelines.
\end{abstract}

Key words: testicular cancer, seminoma, active surveillance, adjuvant chemotherapy, relapse rates

Testicular cancer (TC) represents a rare type of cancer, accounting for $1-2 \%$ of all malignancies in men. However, the incidence rate in many western countries has been increasing for several decades [1], the underlying cause of this phenomenon is not yet scientifically explained. In males between 15-40 years, TC represents the most frequent solid tumor. The majority (approximately $80 \%$ ) of patients with testicular seminomas present with clinical stage I (CSI) [2]. CSI (T1-4, N0, M0) is defined by disease confined to the testis without clinical, serologic, or radiological evidence of regional or disseminated disease.

The Slovak Republic has a relatively high age-standardized rate and placed 8th worldwide $(9.3 / 100,000)$ [1].
National data from the Slovak Republic indicate that $76.9 \%$ of diagnosed seminomas were CSI [3] and the 5-year survival of patients with seminoma testis reached $96.5 \%$ (for the 2003-2007 cohort) [4]. Advances in treatments of patients over the last decades have led to dramatic improvements in disease-free and overall survival. CSI represents one of the most curable malignancies with an excellent outcome after standard primary treatment with radical inguinal orchiectomy. The recurrence rate after surgery is low (generally $5-15 \%)$. The majority of recurrences occur within 2 years after diagnosis [5]. The rate of late relapse ( $>2$ years after primary successful treatment) is estimated to be 1-5\% [6]. Relapses are usually detected by computed tomography scan 
(87\%) and tumor markers evaluation (3\%). Regardless of the previous adjuvant management, recurrences are highly curable with standard therapy with overall survival reaching almost $100 \%$. In the Kollmannsberger study of 1344 CSI patients, the five-year disease-specific survival represented 99.7\% (95\% CI: 99.4-99.9\%) with only 1 death of the patient because of the treatment-related event [7].

Early adjuvant programs were established before the era of highly successful combination chemotherapy in case of relapsed disease. Adjuvant radiotherapy (ART) was the standard treatment for CSI seminoma for the past 60 years. Radiation-associated long-term toxicity includes the risk of second malignant neoplasms (SMNs) (kidney cancer, colorectal cancer, sarcoma, and some leukemias) and cardiovascular disease, both of which are highly relevant in the young patient population [8]. Consequently, European guidelines have removed this treatment option [2, 9]. Adjuvant chemotherapy with a single cycle of carboplatin at a dose of AUC7 has been proposed as an alternative to ART. Oliver in his large phase III trial demonstrated the reduction of the risk of relapse from $15 \%$ to $5 \%$ - comparable to ART with fewer adverse effects, less sick leave, and a significant reduction in contralateral TC $[10,11]$. Some authors have pointed out a possible association between adjuvant chemotherapy and cerebrovascular events [12]. Minimizing treatment-related morbidity in TC patients with a life expectancy comparable to the noncancerous male population is important. Adjuvant therapy may be overtreatment for $80 \%$ to $85 \%$ of patients who are cured by the surgery alone [13]. Accurate risk prediction of relapse is crucial to plan the optimal treatment strategy.

Tumor size $>4 \mathrm{~cm}$ and invasion of the rete testis were associated with an increased risk of relapse in a multiinstitutional retrospective study [14]. Despite the fact that some of the following studies questioned Warde's prognostic model CSI patients [15-17], the Swedish and Norwegian Testicular Cancer Group (SWENOTECA) reported that the presence of either risk factor independently increases the risk of relapse significantly. At a median follow-up of 5.6 years reported relapse rate in patients without risk factors was $4.0 \%$ if managed by surveillance and $2.2 \%$ in patients receiving adjuvant carboplatin compared to $15.5 \%$ in patients with one or both risk factors managed by surveillance and 9.3\% in patients receiving adjuvant carboplatin [18]. Active surveillance (S) is a preferable option for CSI TC patients [19]. Treatment-related toxicity is crucial considering overall survival rates reaching almost $99-100 \%$, regardless of the treatment strategy. While the surveillance allows most patients to avoid additional treatment, it requires an adherence to the follow-up schedule. Low adherence to S protocols may considerably affect the results [17]. Approximately $16 \%$ of patients with seminoma relapse during S [15]. In a clinical scenario like CSI TC, where different disease-management options produce long-term survival rates, unbiased information to the patient and weighing the benefits of surveillance against those of adjuvant treatment while involving patients in individualized decision making is also suggested [17].

The two main risk factors predicting relapse that have been widely studied are primary tumor size $>4 \mathrm{~cm}$ and stromal rete testis invasion (but not pagetoid) (RTI) present in the pathological specimen. A risk-adapted approach seems feasible and showed that the absence of both risk factors predicted an excellent outcome with a 3-year diseasefree survival of $94.9 \%$ [20].

Considering the facts mentioned above, and based on the results from our previous expertise in the field [21], we have decided to design a single-center cross-sectional study to confirm the efficacy of risk-adapted therapeutic approaches ( $\mathrm{S}$ and ACT) for patients with CSI testicular seminoma.

\section{Patients and methods}

Study design. This single-center cross-sectional study analyzed the individual data of 139 CSI pure seminoma patients following orchiectomy who were treated in the St. Elisabeth Cancer Institute, Bratislava, Slovak Republic. The medical records, results of defined laboratory tests, and imaging studies within the period 10/2011 and 5/2020 were reviewed. Patients with spermatocytic seminoma (spermatocytic tumor) were not included in this study. Routine staging procedures consisted of clinical history, physical examination, whole blood cell counts, serum chemistries including determination of tumor markers: lactate dehydrogenase (LDH), $\alpha$-fetoprotein (AFP), and $\beta$-human chorionic gonadotropin ( $\beta$-hCG).

Retroperitoneal lymph nodes involvement was assessed by computed tomography (CT). Malignant/metastatic lymph nodes were identified by the standard lymph node size criterion for a positive scan of $\geq 10 \mathrm{~mm}$ in short axis diameter. Increased values of $\beta$-hCG were acceptable preoperatively. However, the persistence or the increased postoperative $\beta$-hCG levels or any pre- or postoperative AFP were considered as an exclusion criterion.

CSI was defined as a tumor confined to the testis without the evidence of metastasis (normal findings on the chest, abdomen, and pelvis) on radiological imaging at the time of diagnosis. All included patients underwent radical orchiectomy and had histologically confirmed pure seminoma. Tumor markers were normal or normalized after radical orchiectomy.

Patients' stratification. Patients were stratified by the selected risk factors for relapse with risk-adapted therapeutic approaches to the $\mathrm{S}$ group and the ACT group. Informed consent was obtained from all patients from the defined study cohort (according to the inclusion criteria mentioned above). All performed diagnostic and therapeutic procedures followed the current guideline recommendations for patients with TC $[22,23]$ and were consecutively recorded and evaluated. The $S$ group consisted of 77 patients, who were managed with $\mathrm{S}$, consisting of regular life-long follow- 
up after orchiectomy. Tumor markers (LDH, AFP, $\beta$-hCG) were scheduled at months $3,6,9,18,24,36$, and annually thereafter. Initially, thoracic and abdominopelvic CT was performed, subsequently, abdominal CT was performed at month $6,12,18,24,30,36$, and 48 , and annually thereafter. Chest $\mathrm{x}$-ray examinations were not performed. Patients who relapsed during follow-up were treated with the standard platinum-based combination chemotherapy (CHT) - BEP regimen (bleomycin $30 \mathrm{U}$ IV on day 1,8 , and 15 , plus etoposide $100 \mathrm{mg} / \mathrm{m}^{2} \mathrm{IV}$ on days $1-5$, plus cisplatin $20 \mathrm{mg} / \mathrm{m}^{2}$ on days 1-5; every 21 days). According to the ESMO guidelines [2], patients with a complete response did not require further treatment and were followed up. Patients with a residual tumor on the CT scan underwent a [18F] fluorodeoxyglucose-positron emission tomography/computed tomography (FDG-PET/CT) examination with a minimum of 6 weeks after CHT termination.

The ACT group consisted of 62 patients with the presence of RTI and/or a primary tumor size $>4 \mathrm{~cm}$, who received a single cycle of carboplatin at the dosage reaching an area under the curve of $7 \mathrm{mg} / \mathrm{ml} / \mathrm{min}$ ( 7 AUC) in the adjuvant setting.

Statistical analysis. The patients' data were analyzed using descriptive statistics. Continuous variables are reported as means with standard deviations (SD) and medians with ranges, and upper and lower quartiles $\left(\mathrm{Q}_{1}-\mathrm{Q}_{3}\right)$. A two-sample $\mathrm{t}$-test was used to test for between-group differences (ACT vs. S). If the data were skewed, a non-parametric Mann-Whitney U test was used. Categorical variables are presented as counts and relative frequencies, as well as differences between groups, were evaluated using Pearson's $\chi^{2}$ test or Fisher's exact test. Kaplan-Meier survival curves and log-rank tests were used to compare relapse (progression of the disease) by the selected therapeutic approach ACT vs. S. Statistical analyses were performed using StatsDirect 3.0.191 software (Stats Direct Ltd., Cheshire, UK) and Statistica 13 software (Dell-StatSoft, Inc. Tulsa, OK, US). All values were considered significant at a two-tailed p-value $<0.05$.

\section{Results}

A total of 139 adult patients (age $>18$ years) with CSI seminoma were identified and divided into two cohorts depending on the risk-adapted management approach. Of these, 130 patients $(93.5 \%)$ were followed up at a minimum of 6 months after orchiectomy.

The ACT group consisted of 62 patients with a mean age of 38.41 years (median 37.12 years, range 47.68 (19.95$67.63)$ years)) at the time of diagnosis. Five (8.1\%) patients relapsed. The mean time to relapse was $11.6 \pm 3.43$ months (median 13, range 8 (7-15) months)) (Table 1).

The $S$ group consisted of 77 patients with a mean age of 39.28 years (median 39.92 years, range 42.17 (18.68$60.85)$ years) at the time of diagnosis; of which $10(13.0 \%)$
Table 1. Patients characteristics.

\begin{tabular}{|c|c|c|c|}
\hline Age at diagnosis & ACT & $\mathbf{S}$ & Summa \\
\hline Absolute number & 62 & 77 & 139 \\
\hline Mean age (years) $\pm S D$ & $38.41 \pm 9.29$ & $39.28 \pm 9.87$ & $38.89 \pm 9.59$ \\
\hline Median & 37.12 & 39.92 & 38.11 \\
\hline (Q1-Q3) & $(32.03-43.30)$ & $(31.13-44.71)$ & $(31.75-44.11)$ \\
\hline Age min (years) & 19.95 & 18.68 & 18.68 \\
\hline Age max (years) & 67.63 & 60.85 & 67.63 \\
\hline Range & 47.68 & 42.17 & 48.95 \\
\hline \multicolumn{4}{|l|}{ Follow-up } \\
\hline \multicolumn{4}{|l|}{ Mean follow-up } \\
\hline (months) $\pm \mathrm{SD}$ & $38.83 \pm 26.14$ & $48.14 \pm 28.06$ & $43.99 \pm 27.52$ \\
\hline Median & 35.66 & 48.00 & 45.50 \\
\hline (Q1-Q3) & $(15.31-59.76)$ & $(26.84-63.41)$ & $(20.69-61.50)$ \\
\hline Time min (months) & 1.01 & 1.28 & 1.01 \\
\hline Time max (months) & 97.05 & 99.44 & 99.44 \\
\hline Range & 96.03 & 98.16 & 98.43 \\
\hline Progression rate (\%) & $5(8.1 \%)$ & $10(13.0 \%)$ & $15(10.79 \%)$ \\
\hline Mean time \pm SD (months) & $11.6 \pm 3.43$ & $14.3 \pm 7.04$ & $13.4 \pm 6.08$ \\
\hline Median & 13 & 14 & 13 \\
\hline (Q1-Q3) & $(9-14)$ & $(6-21)$ & $(7-21)$ \\
\hline Time min (months) & 7 & 5 & 5 \\
\hline Time max (months) & 15 & 22 & 22 \\
\hline Range & 8 & 17 & 17 \\
\hline
\end{tabular}

patients experienced a relapse. The mean time to relapse was 14.3 \pm 7.04 months (median 14 months, range 17 (5-22) months); however, in 5 (50\%) patients the relapse occurred within 12 months.

All of the relapses from both cohorts were located in the retroperitoneal lymph nodes. At the time of relapse, patients were treated with three cycles of cisplatin based CHT - BEP. All of the relapsed patients achieved a complete response after treatment defined as the disappearance of all clinical, and biochemical signs further confirmed using post-chemotherapy FDG-PET/CT scanning.

Patients with both risk factors (presence of RTI and primary tumor size $>4 \mathrm{~cm}$ ) relapsed following ACT in 5/66 $(8.1 \%)$. In the group of patients with one risk factor, no relapses were observed.

There wasn't a statistically significant difference in the age-distribution of patients (at the time of their diagnosis) (the nonsignificant difference between the mean of age: $\mathrm{p}=0.596$ and the nonsignificant difference between the median of age: $p=0.4281$ ), when comparing the groups $\mathrm{S}$ and ACT. Considering these facts, we tested the differences in progression-free survival (PFS). However, we didn't find any statistically significant differences in PFS when comparing these two study groups $(\mathrm{p}=0.4184)$. On the other hand, 5 cases (out of 62) of the relapses registered in the group ACT, might be related to relatively small numbers of subjects in 
the cross-sectional study (Figure 1). The overall survival rate of all CSI testicular seminoma patients in both groups has reached $100 \%$ (up to May 31, 2020) with a mean follow-up of 43.99 months (median 38.11 months, range 96.03 (1.0199.44) months) following orchiectomy.

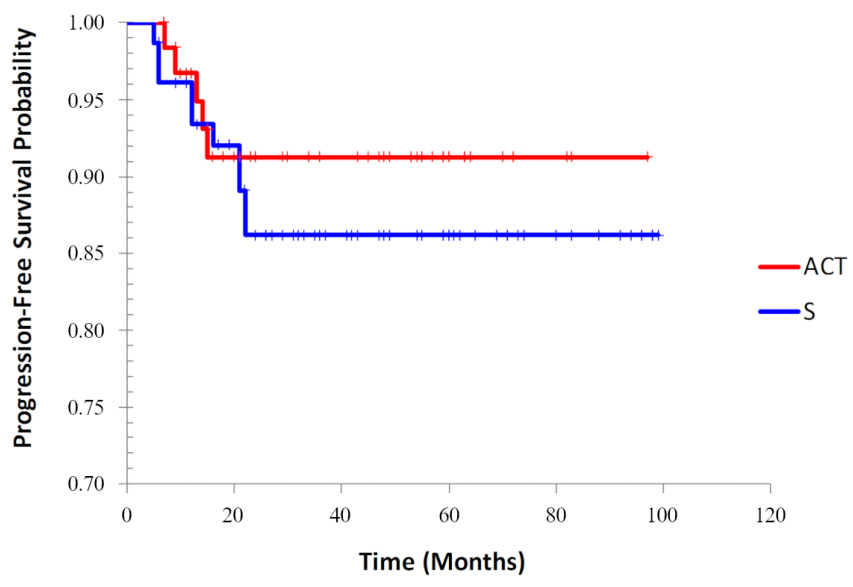

Figure 1. Progression-free survival in patients subjected to active surveillance (S) versus adjuvant chemotherapy $(\mathrm{ACT})$.

\section{Discussion}

Despite its' confirmed effectiveness, the adjuvant treatment of CSI testicular seminoma represents overtreatment for the majority of patients who are cured by the surgery alone. The accurate risk prediction of relapse is essential to avoid the potentially serious long-term consequences including cardiovascular toxicity, cerebrovascular toxicity, and SMNs $[12,24]$.

Traditionally ART was administered to the ipsilateral renal hilum, pelvic lymph nodes, and the bilateral paraaortic/retroperitoneal nodes („dog-leg“) with excellent results with 5-year relapse-free survival rates in excess of 94\% [25]. Other strategies limited the radiation field to the paraaortic nodes ("PA strip") or aimed to decrease the dose of irradiation with comparable results [26-28]. Nevertheless, for patients with CSI testicular seminoma, the option of ART has been removed from the European guidelines on TC due to the risk of long-term toxicity, represented by the radiation-induced SMNs $[9,23]$.

Single-agent carboplatin is an alternative to ART with comparable results and fewer adverse effects, and a significant reduction in contralateral TC $[10,11]$. However, indication in the low-risk patient is not justified [18]. Results of

Table 2. Recommended minimal follow-up protocols for stage I seminoma on active surveillance or after adjuvant treatment (carboplatin or radiotherapy) [23, 35, and https://www.nccn.org/professionals/physician_gls/pdf/testicular.pdf].

\begin{tabular}{|c|c|c|c|c|c|}
\hline MODALITY & YEAR 1 & YEAR 2 & YEAR 3 & YEAR 4 & YEAR 5 \\
\hline \multicolumn{6}{|l|}{ European Association of Urology } \\
\hline tumor markers, $+/-$ doctor visit & 2 times & 2 times & 2 times & once & According to \\
\hline abdominopelvic CT/ MR & 2 times & 2 times & once at 36 months & once at 60 months & survivorship care \\
\hline chest $\mathrm{X}$-ray & - & - & - & - & \\
\hline \multicolumn{6}{|l|}{ National Comprehensive Cancer Network } \\
\hline \multicolumn{6}{|l|}{ Surveillance after orchiectomy } \\
\hline doctor visit, serum markers optional & $2-4$ times & 2 times & $1-2$ times & once & once \\
\hline abdominal $+/$ - pelvic CT & at 3,6 and 12 months & 2 times & $1-2$ times & \multicolumn{2}{|c|}{ every 12-24 months } \\
\hline chest X-ray & \multicolumn{5}{|c|}{ As clinically indicated, consider chest CT with contrast in symptomatic patients. } \\
\hline \multicolumn{6}{|c|}{ Surveillance after adjuvant treatment (chemotherapy/radiation) } \\
\hline doctor visit, serum markers optional & $1-2$ times & $1-2$ times & once & once & once \\
\hline abdominal $+/-$ pelvic CT & once & once & once & - & - \\
\hline chest X-ray & \multicolumn{5}{|c|}{ As clinically indicated, consider chest CT with contrast in symptomatic patients. } \\
\hline \multicolumn{6}{|l|}{ European Society for Medical Oncology } \\
\hline tumor markers, $+/-$ doctor visit & 2 times & 2 times & 2 times & once & once \\
\hline abdominal CT/ MR & 2 times & 2 times & once at 36 months & once at 60 months & \\
\hline chest X-ray & - & - & - & - & \\
\hline \multicolumn{6}{|l|}{ St. Elisabeth Cancer Institute protocol } \\
\hline doctor visit, serum markers optional & at 3,6 and 9 months & $\begin{array}{l}2 \text { times at } 18 \text { and } \\
24 \text { months }\end{array}$ & $\begin{array}{l}2 \text { times at } 30 \text { and } \\
36 \text { months }\end{array}$ & once & once \\
\hline abdominal CT & $\begin{array}{l}2 \text { times } \\
\text { at } 6 \text { and } 12 \text { months }\end{array}$ & $\begin{array}{l}2 \text { times at } 18 \text { and } \\
24 \text { months }\end{array}$ & $\begin{array}{l}2 \text { times at } 30 \text { and } \\
36 \text { months }\end{array}$ & once & once \\
\hline chest X-ray & \multicolumn{5}{|c|}{$\begin{array}{l}\text { Not performed. Initially performed thoracic and abdominopelvic CT, afterwards if clinically indicated } \\
\text { with contrast in symptomatic patients. }\end{array}$} \\
\hline
\end{tabular}


a recent large retrospective study of 11,206 patients suggest an increase in the use of ACT [29]. Considering the high cure rate in the case of relapse, the majority of the patients are managed by S. However, the optimal treatment strategy of CSI testicular seminoma is highly controversial and generates debate at each consensus meeting on TC $[9,22]$. There are no randomized trials to prove the superiority of $S$ or adjuvant treatment and solid data to define patients with a high risk of relapse, who would benefit from up-front adjuvant treatment, are missing. The accurate risk prediction of relapse is crucial to plan the optimal treatment strategy. Stratification based on the risk factors may lead to individualized treatment and follow-up programs, with lower morbidity and costs for the health system.

Primary tumor size $>4 \mathrm{~cm}$ and/or RTI were identified as independent risk factors for relapse in prospective nonrandomized studies, with an incremental rise in the 5 -year relapse rate in the presence of zero, one, or both of these factors $(12.2 \%, 15.9 \%$, and $31.5 \%$, respectively) [30]. The results of the present study have the potential to affirm mentioned risk factors in order to stratify patients into high- and low-risk groups based on their risk of relapse. In our group of CSI testicular seminoma patients without the presence of risk factors have been managed by $S$, the relapse rate was determined to be $11.9 \%$.

All relapses were located in the retroperitoneal lymph nodes. Risk factors associated with relapse are weak and controversial. Warde et al. [14] in their study were the first to show that patients having one or both risk factors (primary tumor size $>4 \mathrm{~cm}$, presence of RTI) present in the pathological specimen were at a higher risk of relapse than the patients without these risk factors. RTI was found to be a predictive factor for relapse in another Japanese study [31], but it wasn't confirmed in the nationwide Danish study [32]. Zengerling et al. [33] in their large systematic review of 19 studies conducted 20 years after Warde et al. [14] found superiority of tumor size compared to rete testis infiltration in terms of being prognostic for tumor recurrence.

In one study, Tandstad et al. [18], reporting for the SWENOTECA, prospectively evaluated the efficacy of one cycle of carboplatin in a population-based cohort of 897 patients with CSI seminoma. Active surveillance was recommended for patients whose tumors had 0 or 1 risk factor, whereas patients whose tumors had both risk factors were offered ACT. Regardless of the risk factor recommendation, patients were free to choose between ACT and S. With a median follow-up of 5.6 years, 69 relapses were reported. The relapse rate in $\mathrm{S}$ was $4.0 \%$ in case of no risk factors, $19.1 \%$ when the primary tumor size was $>4 \mathrm{~cm}$ only, $13.6 \%$ with the presence of RTI only, and $16.7 \%$ when both risk factors were present; in the combined group of patients with either one or two risk factors, the relapse rate was $15.5 \%$. In patients who received one cycle of carboplatin, the relapse rate was $2.2 \%$ in case of no risk factors, $9.7 \%$ with a primary tumor size $>4 \mathrm{~cm}$ only, $9.1 \%$ with the presence of RTI only,
9.3\% with either risk factor, and $10.4 \%$ when both risk factors were present [18].

In the study of Dieckmann et al. [34] with 725 eligible patients with CSI seminoma managed with different therapeutic modalities, one course of adjuvant carboplatin was linked to relapses in $6.8 \%$ of patients with primary tumor size $>4 \mathrm{~cm}$, the highest relapse rate was $9.1 \%$, in the group of patients where both risk factors were present. In the S group, the relapse rate was $7.7 \%$ if RTI was not found and $8.6 \%$ if primary tumor size was $<4 \mathrm{~cm}$ [34].

In our group of CSI testicular seminoma patients managed by ACT, we identified relapse in $8.1 \%$. All relapsed patients were treated with $3 \times \mathrm{BEP}$ CHT. PET/CT was the method of assessment of the treatment response. All patients from our ACT study group were alive at the time of study completion; with a mean follow-up of 38.83 months and with no evidence of disease.

The PET-CT is a valuable tool for clinical decisionmaking in post-chemotherapy seminoma residual masses. FDG-PET-CT may be helpful to assess residual masses $>3$ $\mathrm{cm}$ in patients with seminoma if carried out at least 8 weeks after the end of CHT $[35,36]$. This examination is more reliable than $\mathrm{CT}$ in predicting necrosis/fibrosis or viable tumor, and thus able to spare patients unnecessary additional treatment such as surgery or radiotherapy. The advantage of the FDG-PET/CT is certainly the fact that a whole-body scan is performed, allowing all tissues and organs to be evaluated in a single-step examination. Moreover, the PET/ CT can identify metabolically active tissues and therefore the presence of viable tumor cells, which require further treatment [37]. The outcome of the S policy in CSI testicular seminoma, together with the availability of curative CHT for early metastatic disease and improvement of diagnostic imaging has led to the introduction of the S strategy in CSI testicular seminoma.

The median time to relapse post-orchiectomy for CSI testicular seminoma ranges from 12-18 months, but up to $29 \%$ of relapses can develop later [23]. In the largest published series describing clinical outcome and relapse data of patients with CSI testicular seminoma treated with one cycle of ACT with carboplatin, 21/517 patients (4.1\%) have relapsed, the median time to relapse was 22.7 months, with no relapses detected before 12.5 months [38]. Fisher et al. [39] observed the earliest relapse 4 months after orchiectomy, the latest relapse after 15 years, the median time from orchiectomy to relapse was 19 months. The most common site of relapse was the paraaortic lymph nodes (in up to $82 \%)$, in contrast to the findings from our current study, in which all patients experienced a relapse in the retroperitoneal lymph nodes (100\%).

We also identified similar ranges of the median of the time to relapse (14.3 months) without statistically significant difference in PFS between patients managed by $S$ or ACT. Relapses can be successfully treated by platinum-based (BEP regimen) CHT. All patients from our ACT study group 
(after previous BEP treatment) were alive (at the time of study completion) with no evidence of disease. According to the recent EAU Guidelines, due to high rates of relapse, and common late recurrences, close and active follow-up for at least 5 years is mandatory [23].

Chau et al. [40] declare that the time to ACT did not appear to influence the outcome, although $75 \%$ of their patients received CHT within 60 days post-orchiectomy. Given the late toxicity of ART (particularly SMN) and higher relapse rate of $S$, it is not surprising that ACT has emerged as a further option in the management of CSI testicular seminoma in recent years [40]. According to recent EAU Guidelines, ART is not recommended as adjuvant treatment for this malignancy $[23,35]$.

The question of optimal management of CSI testicular cancer remains controversial among experts at high-volume centers throughout the world. The main controversy is whether to overtreat a substantial number of patients with CSI disease to prevent relapse, or to observe and treat only patients who experience relapse as ACT and S strategy both bring curative outcome $[41,42]$.

The basic principle of active surveillance remains consistent; to perform initially frequent evaluations after surgery in order to detect an early cancer recurrence and then initiate further treatment. The follow-up visits consist of a history and physical examination, but the timing and choice of imaging examinations may vary significantly in centers; including X-rays, CT scans, and magnetic resonance (MR). Important distinctions between the National Comprehensive Cancer Network (NCCN), EAU, and Multicenter Collaborative Expert Opinion include the optional use of serum marker evaluation such as LDH, AFP, $\beta$-hCG. The evaluation of serum hormone levels (total testosterone, luteinizing hormone, and follicle-stimulating hormone) is also included in some of the S protocols. Further refinements of the protocols will likely minimize chest imaging, especially in patients with CSI without abdominal or serologic relapse $[43,44]$. Based on the decades of experience and ubiquity of this imaging modality, the CT scan of the abdomen was used to survey the TC patients. However, the latest evidence from the SWENOTECA trials suggests that CT should be avoided in the follow-up of patients and replaced by an MR examination $[23,45]$. The comparison between surveillance protocol recommendations and protocol used in our clinical trial is further summarized in Table 2 [23, 35, and https://www. nccn.org/professionals/physician_gls/pdf/testicular.pdf].

In conclusion, the current study confirms that active surveillance is a safe approach in CSI testicular seminoma patients, of which the majority can avoid further treatment after orchiectomy. The benefit of using risk-adapted approaches in CSI testicular seminoma patients is evident; however, it requires a long-term follow-up and experience with the management of this type of malignancy. The advantages and disadvantages of the various treatment modalities are still being discussed [46].
Acknowledgments: The authors declare no potential conflicts of interest and received no financial support with respect to the research, authorship, and publication of this article.

\section{References}

[1] BRAY F, FERLAY J, SOERJOMATARAM I, SIEGEL RL, TORRE LA et al. Global cancer statistics 2018: GLOBOCAN estimates of incidence and mortality worldwide for 36 cancers in 185 countries. CA Cancer J Clin 2018; 68: 394-424. https://doi.org/10.3322/caac.21492

[2] OLDENBURG J, FOSSA SD, NUVER J, HEIDENREICH A, SCHMOLL HJ et al. Testicular seminoma and non-seminoma: ESMO in clinical practice guidelines for diagnosis, treatment and follow-up. Ann Oncol 2015; 26: 833-838. https:// doi.org/10.1093/annonc/mdu514

[3] ONDRUS D, ONDRUSOVA M, DUSEK L. Recent patterns in testicular cancer incidence, mortality and survival in the Slovak Republic with reference to international comparison. Cancer Invest 2012; 30: 545-551. https://doi.org/10.3109/07 357907.2012.700984

[4] ONDRUS D, ONDRUSOVA M, SUCHANSKY M. Recent trends in survival of testicular cancer patients - nation-wide population-based study. Klin Onkol Spring 2018; 31: 137142. https://doi.org/10.14735/amko2018137

[5] BOORMANS JL, MAYOR de CASTRO J, MARCONI L, YUAN Y, LAGUNA PES MP et al. Testicular Tumour Size and Rete Testis Invasion as Prognostic Factors for the Risk of Relapse of Clinical Stage I Seminoma Testis Patients Under Surveillance: a Systematic Review by the Testicular Cancer Guidelines Panel. Eur Urol 2018; 73: 394-405. https://doi. org/10.1016/j.eururo.2017.09.025

[6] MORTENSEN MS, LAURITSEN J, KIER MG, BANDAK M, APPELT AL et al. Late Relapses in Stage I Testicular Cancer Patients on Surveillance. Eur Urol 2016; 70: 365-371. https:// doi.org/10.1016/j.eururo.2016.03.016

[7] KOLLMANNSBERGER C, TANDSTAD T, BEDARD PL, COHN-CEDERMARK G, CHUNG PW et al. Patterns of relapse in patients with clinical stage I testicular cancer managed with active surveillance. J Clin Oncol 2015; 33: 51-57. https://doi.org/10.1200/JCO.2014.56.2116

[8] TRAVIS LB, NG AK, ALLAN JM, PUI CH, KENNEDY AR et al. Second malignant neoplasms and cardiovascular disease following radiotherapy. J Natl Cancer Inst 2012; 104: 357-370. https://doi.org/10.1093/jnci/djr533

[9] BEYER J, ALBERS P, ALTENA R, APARICIO J, BOKEMEYER C et al. Maintaining success, reducing treatment burden, focusing on survivorship: Highlights from the third European consensus conference on diagnosis and treatment of germ-cell cancer. Ann Oncol 2013; 24: 878-888. https://doi. org/10.1093/annonc/mds579

[10] OLIVER RTD, MASON MD, MEAD GM, VON DER MAASE H, RUSTIN GJS et al. Radiotherapy versus singledose carboplatin in adjuvant treatment of stage I seminoma: a randomized trial. Lancet 2005; 366: 293-300. https://doi. org/10.1016/S0140-6736(05)66984-X 
[11] OLIVER RTD, MEAD GM, RUSTIN GJS, JOFFE JK, AASS $\mathrm{N}$ et al. Randomized trial of carboplatin versus radiotherapy for stage I seminoma: mature results on relapse and contralateral testis cancer rates in MRC TE19/EORTC 30982 study (SRCTN27163214). J Clin Oncol 2011; 29: 957-962. https:// doi.org/10.1200/JCO.2009.26.4655

[12] POWLES T, ROBINSON D, SHAMASH J, MOLLER H, TRANTER $\mathrm{N}$ et al. The long-term risks of adjuvant carboplatin treatment for stage I seminoma of the testis. Ann Oncol 2008; 19: 443-447. https://doi.org/10.1093/annonc/ mdm540

[13] NAPPI L, NICHOLS CR, KOLLMANNSBERGER CK. New treatments for stage I testicular cancer. Clin Adv Hematol Oncol 2017; 15: 626-631.

[14] WARDE P, SPECHT L, HORWICH A, OLIVER T, PANZARELLA T et al. Prognostic factors for relapse in stage I seminoma managed by surveillance: a pooled analysis. J Clin Oncol 2002; 20: 4448-4452. https://doi.org/10.1200/ JCO.2002.01.038

[15] TANDSTAD T, SMAALAND T, SOLBERG A, BREMNES RM, LANGBERG CW et al. Management of seminomatous testicular cancer: a binational prospective population-based study from the SWENOTECA study group. J Clin Oncol 2011; 29: 719-725. https://doi.org/10.1200/ JCO.2010.30.1044

[16] CHUNG P, DAUGAARD G, TYLDASLEY S, ATENAFU EG, PANZARELLA T et al. Evaluation of a prognostic model for risk of relapse in stage I seminoma surveillance. Cancer Med 2015; 4: 155-160. https://doi.org/10.1002/ cam4.324

[17] OLDENBURG J, APARICIO J, BEYER J, COHN-CEDEMARK G, CULLEN $M$ et al. Personalizing, not patronizing: the case for patient autonomy by unbiased presentation of management options in stage I testicular cancer. Ann Oncol 2015; 26: 833-838. https://doi.org/10.1093/annonc/ mdu514

[18] TANDSTAD T, STAHL O, DAHL O, HAUGNES HS, HAKANSSON U et al. Treatment of stage I seminoma, with one course of adjuvant carboplatin or surveillance, riskadapted recommendations implementing patient autonomy: A report from the Swedish and Norwegian Testicular Cancer Group (SWENOTECA). Ann Oncol 2016; 27: 1299-1304. https://doi.org/10.1093/annonc/mdw164

[19] NICHOLS CR, ROTH B, ALBERS P, EINHORN LH, FOSTER R et al. Active surveillance is the preferred approach to clinical stage I testicular cancer. J Clin Oncol 2013; 31: 34903493. https://doi.org/10.1200/JCO.2012.47.6010

[20] APARICIO J, SANCHEZ-MUNOZ A, GUMA J, DOMENECH M, MEANA JA et al. A risk-adapted approach to patients with stage I testicular seminoma according to the status of rete testis: the fourth Spanish Germ Cell Cancer Group Study. Oncology 2018; 95: 8-12. https://doi. org/10.1159/000487438

[21] ONDRUSOVA M, BALOGOVA S, LEHOTSKA V, KAJO K, MRINAKOVA B et al. Controversies in the management of clinical stage I testicular seminoma. Cent European J Urol 2016; 69: 35-39. https://doi.org/10.5173/ceju.2016.699
[22] KREGE S, BEYER J, SOUCHON R, ALBERS P, ALBRECHT $\mathrm{W}$ et al. European consensus conference on diagnosis and treatment of germ cell cancer: a report of the second meeting of the European Germ Cell Cancer Consensus Group (EGCCCG): part I. Eur Urol 2008; 53: 478-496. https://doi. org/10.1016/j.eururo.2007.12.024

[23] ALBERS P, ALBRECHT W, ALGABA F, BOKEMEYER C, COHN-CEDERMARK G et al. Guidelines on testicular cancer: 2015. Update. Eur Urol 2015; 68: 1054-1068. https://doi. org/10.1016/j.eururo.2015.07.044

[24] WAGNER T, TOFT BG, ENGVAD B, LAURITSEN J, KREIBERG $\mathrm{M}$ et al. Prognostic factors for relapse in patients with clinical stage I testicular cancer: protocol for a Danish nationwide cohort study. BMJ Open 2019; 9: e033713. https:// doi.org/10.1136/bmjopen-2019-033713

[25] CHUNG P, WARDE P. Surveillance in stage I seminoma. Urol Oncol 2006; 24: 75-79. https://doi.org/10.1016/j. urolonc.2005.07.007

[26] FOSSA SD, HORWICH A, RUSSELL JM, ROBERTS JT, CULLEN $\mathrm{MH}$ et al. Optimal planning target volume for stage I testicular seminoma: A Medical Research Council randomized trial. Medical Research Council Testicular Tumor Working Group. J Clin Oncol 1999; 17: 1146. https:// doi.org/10.1200/JCO.1999.17.4.1146

[27] JONES WG, FOSSA SD, MEAD GM, ROBERTS JT, SOKAL $\mathrm{M}$, et al. Randomized trial of 30 versus 20 Gy in the adjuvant treatment of stage I Testicular Seminoma: a report on Medical Research Council Trial TE18, European Organisation for the Research and Treatment of Cancer Trial 30942 (ISRCTN18525328). J Clin Oncol 2005; 23: 1200-1208. https:// doi.org/10.1200/JCO.2005.08.003

[28] KHAN O, PROTHEROE A. Testis cancer. Postgrad Med J 2007; 83: 624-632. https://doi.org/10.1136/ pgmj.2007.057992

[29] MISRTETTA FA, MAZZONE E, PALUMBO C, KNIPPER S, TIAN Z et al. Contemporary Assessment of Survival Rates in Stage I Testicular Seminoma: A Population-Based Comparison Between Surveillance and Active Treatment After Orchiectomy. Clin Genitourin Cancer 2019; 17: e793-e801. https://doi.org/10.1016/j.clgc.2019.04.015

[30] WARDE P, GOSPODAROWICZ M. Evolving concepts in stage I seminoma. BJU Int 2009; 104: 1357-1361. https://doi. org/10.1111/j.1464-410X.2009.08859.x

[31] KAMBA T, KAMOTO K, OKUBO S, TARAMUKAI S, KAKEHI Y et al. Outcome of different post-orchiectomy management for stage I seminoma: Japanese multi-institutional study including 425 patients. Int J Urol 2010; 17: 980-987. https://doi.org/10.1111/j.1442-2042.2010.02645.x

[32] MORTENSEN MS, LAURITSEN J, GUNDGAARD MG, AGERBAEK M, HOLM NV et al. A nationwide cohort study of stage I seminoma patients followed on a surveillance program. Eur Urol 2014; 66: 1172-1178. https:/doi. org/10.1016/j.eururo.2014.07.001

[33] ZENGERLING F, KUNATH F, JENSEN K, RUF C, SCHMIDT S et al. Prognostic factors for tumor recurrence in patients with clinical stage I seminoma undergoing surveillance- A systemic review. Urol Oncol 2018; 36: 448-458. https://doi.org/10.1016/j.urolonc.2017.06.047 
[34] DIECKMANN KP, DRALLE-FILIZ I, MATTHIES C, HEINZELBECKER J, BEDKE J et al. Testicular seminoma clinical stage 1: treatment outcome on a routine care level. J Cancer Res Clin Oncol 2016; 142: 1599-1607. https://doi. org/10.1007/s00432-016-2162-z

[35] HONECKER F, APARICIO J, BERNEY D, BEYER J, BOKEMEYER C et al. ESMO Consensus Conference on testicular germ cell cancer: diagnosis, treatment and follow-up. Ann Oncol 2018; 29: 1658-1686. https://doi.org/10.1093/annonc/ mdy 217

[36] BUCHLER T, SIMONOVA K, FENCL P, ABRAHAMOVA J. Positron emission tomography in the diagnosis and monitoring of patients with nonseminomatous germ cell tumours. Klin Onkol 2011; 24: 413-417.

[37] AMBROSINI V, ZUCCHINI G, NICOLINI S, BERSELLI A, NANNI C et al. 18F-FDG PET/CT impact on testicular tumours clinical management. Eur J Nucl Med Mol Imaging 2014; 41: 668-673. https://doi.org/10.1007/s00259-0132624-3

[38] SIEKIERA J, MALKOWSKI B, JOZWICKI W, JASINSKI M, WRONCZEWSKI A et al. Can we rely on PET in the follow-up of advanced seminoma patients? Urol Int 2012; 88: 405-409. https://doi.org/10.1159/000337056

[39] FISCHER S, TANDSTAD T, WHEATER M, PORFIRI E, FLECHON A et al. Outcome of men with relapse after adjuvant carboplatin for clinical stage I seminoma. J Clin Oncol 2017; 35: 194-200. https://doi.org/10.1200/ JCO.2016.69.0958
[40] CHAU C, CATHOMAS R, WHEATER M, KLINGBIEL $D$, FEHR $M$ et al. Treatment outcome and patterns of relapse following adjuvant carboplatin for stage I testicular seminomatous germ cell tumour: results from a 17 year UK experience. Ann Oncol 2015; 26: 1865-1870. https://doi. org/10.1093/annonc/mdv254

[41] PECTASIDES D, PECTASIDES E, CONSTANTINIDOU A, ARAVANTINOS G. Stage I testicular seminoma: management and controversies. Crit Rev Oncol Hematol 2009; 71: 22-28. https://doi.org/10.1016/j.critrevonc.2008.10.007

[42] CHOVANEC M, HANNA N, CARY KC, EINHORN LH, ALBANY C. Management of stage I testicular germ cell tumours. Nat Rev Urol 2016; 13: 663-673. https://doi. org/10.1038/nrurol.2016.164

[43] LIENG H, WARDE P, BEDARD P, HAMILTON RJ, HANSEN AR et al. Recommendations for follow-up of stage I and II seminoma: The Princess Margaret Cancer Centre approach. Can Urol Assoc J 2018; 12: 59-66. https://doi. org/10.5489/cuaj.4531

[44] PIERORAZIO PM, ALBERS P, BLACK PC, TANDSTAD T, HEIDENREICH A et al. Non-risk-adapted Surveillance for Stage I Testicular Cancer: Critical Review and Summary. Eur Urol 2018; 73: 899-907. https://doi.org/10.1016/j.eururo.2017.12.030

[45] MOSAVI F, LAURELL A, AHLSTROM H. Whole Body MRI, Including Diffusion-Weighted Imaging in Follow-Up of Patients with Testicular Cancer. Acta Oncol 2015; 54: 1763 1769. https://doi.org/10.3109/0284186X.2015.1043027

[46] VYSKOCIL J, POPRACH A, PETRAKOVA K, LAKOMY R, VYZULA R, COUPEK P. Treatment of seminoma I stage disease. Klin Onkol 2008; 21: 86-92. 